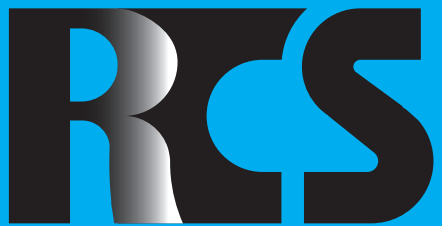

Depósito legal ppi $201502 Z U 4662$

Esta publicación científica en formato

digital es continuidad de la revista impresa

Depósito Legal: pp $197402 Z U 789$

ISSN: 1315-9518

\title{
Revista de Ciencias Sociales
}

Universidad del Zulia. Revista de la Facultad de Ciencias Económicas y Sociales Vol. XXV. Número especial 1, 2019

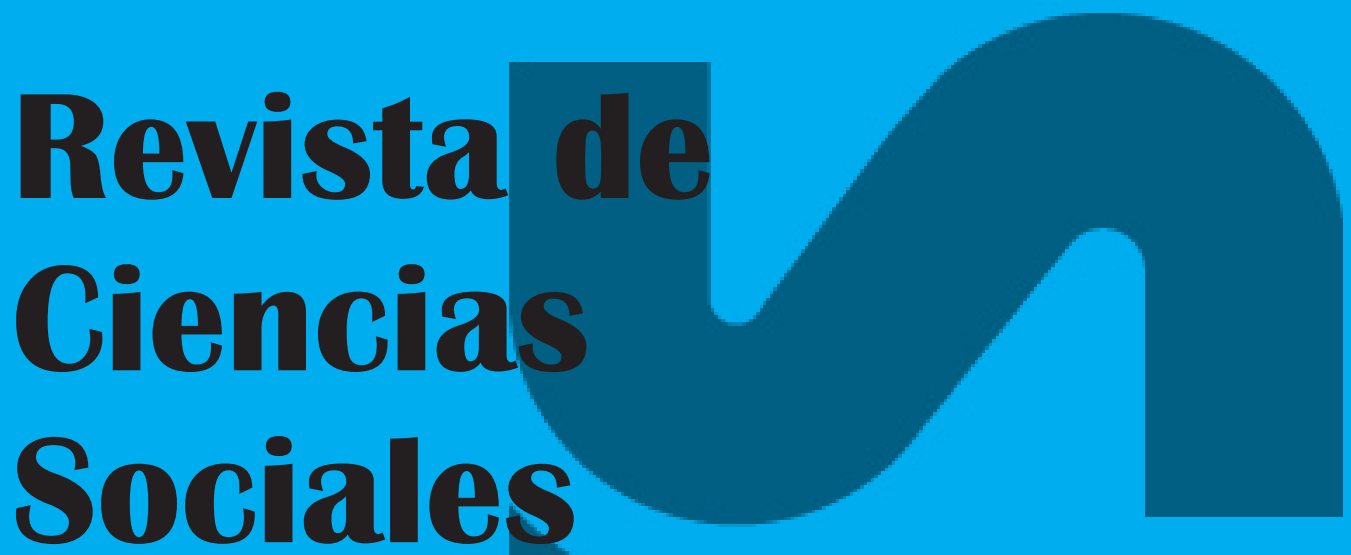




\title{
Unión Europea y Japón: ¿El tratado de libre comercio más grande del mundo?
}

\author{
Baena Rojas, José Jaime* \\ Cardona Montoya, Giovanny**
}

\section{Resumen}

Durante más de un lustro la Unión Europea y Japón han venido llevando a cabo una compleja negociación para alcanzar la firma de un Tratado de Libre Comercio que reduzca en general las barreras arancelarias e igualmente las no arancelarias a razón de liberalizar el tráfico de mercancías. Por lo tanto, tras la ratificación del presente acuerdo comercial este artículo tiene como objetivo analizar algunas características generales de esta nueva zona de libre comercio, y sus partes implicadas. Así tras llevarse a cabo un análisis descriptivo los resultados indican que el presente Tratado de Libre Comercio supone un interesante paradigma para el comercio exterior entre la Unión Europea y Japón, como también para el comercio internacional en cuanto a acuerdos comerciales se refiere. Se concluye que este Tratado hoy por hoy, es el más grande del mundo puesto que representa aproximadamente un $27,45 \%$ del Producto Interno Bruto total mundial, un $37,13 \%$ de las exportaciones mundiales y un $27,45 \%$ de las importaciones mundiales.

Palabras clave: Tratado de Libre Comercio; zona de libre comercio; Unión Europea; Japón; comercio internacional.

* Doctor en Derecho y Ciencias Política (Universidad de Barcelona, España). Magister en Internacionalización. Especialista en Comercio Internacional (EUDE Business School, España). Pregrado en Ciencia Política (Universidad Nacional de Colombia). Profesor e Investigador Institución Universitaria CEIPA (Centro de Investigación y Planeamiento Administrativo), Colombia. E-mail: jose. baena@ceipa.edu.co ORCID: https://orcid.org/0000-0002-0915-4087

** Doctor en Ciencias Pedagógicas (Universidad Hermanos Saiz Monte de OCA, Cuba). Magister en Integración y Cooperación Internacional (Universidad Nacional de Rosario, Argentina). Especialista en Integración Regional. Pregrado en Economía en Relaciones Internaciones (Universidad Estatal de Kiev, Ucrania). Profesor y Vicerrector académico Institución Universitaria CEIPA (Centro de Investigación y Planeamiento Administrativo), Colombia. E-mail: giovanny.cardona@ceipa.edu.co ORCID: https:// orcid.org/0000-0003-2253-3580 


\title{
European Unión and Japan: The biggest free trade agreement in the world?
}

\begin{abstract}
For more than five years the European and Japan Union have been carrying out a complex negotiation in order to reach the signing of a Free Trade Agreement that allows to reduces generally the tariff barriers and also non-tariff barriers in order to liberalize the merchandise traffic. Therefore, after the ratification of this commercial agreement, this article aims to analyze some general characteristics of this new free trade zone, and its stakeholders. So, having applied a descriptive analysis, the results indicate that this Free Trade Agreement represents an interesting paradigm for foreign trade among the European Union and Japan, as well as for international trade in terms of trade agreements. In conclusion, nowadays this trade is the biggest of the world due itself represents around a $27,45 \%$ of the wolrd's gross domestic product, $37,13 \%$ of world exports and $27,45 \%$ of world imports.
\end{abstract}

Keywords: Free Trade Agreement; free trade zone; European Union; Japan; international trade.

\section{Introducción}

El sistema multilateral de comercio ha logrado erigirse tras más de siete décadas de diversas negociaciones comerciales, las cuales tuvieron lugar en el marco del Acuerdo General sobre Aranceles Aduaneros y Comercio o General Agreement on Tariffs and Trade (GATT) en $1947 \mathrm{y}$ que se han mantenido con la creación de la Organización Mundial de Comercio (OMC) en 1995, en un intento notable por procurar la reducción sustancial de las Barreras Arancelarias (BA) y Barreras No Arancelarias (BNA) además de apuntar a la supresión del trato discriminatorio en las relaciones económicas de los países (Basaldúa, 2014).

Así se puede afirmar, que las vicisitudes actuales de la economía mundial están cambiando substancialmente los parámetros del desarrollo social en todos los países, que se ven enfrentados a un desafío que consiste en lograr vincular la globalización económica y comercial, que está impulsando el cambio en las estructuras de producción, en las relaciones laborales, comerciales y de inversión, con la soberanía misma de los Estados y sus propias políticas sociales, dentro del sistema multilateral de comercio (Fernández, 2009; Muñoz, Cabrita, Ribeiro y Diéguez, 2015).

Esta es en parte la razón por la cual parece que con mayor regularidad se ha disparado la firma de acuerdos comerciales, los cuales cada vez son más populares dentro de la política de comercio exterior de los países, tal y como supone el artículo XXIV, el cual reconoce la conveniencia de incrementar el libre comercio por medio de figuras como las uniones aduaneras y zonas de libre comercio (Lacarte y Granados, 2004; Cardona, 2018). Lo anterior especialmente cuando el tema del proteccionismo parece tomar una vez más una significativa importancia, considerando el aumento de las BA y especialmente de las BNA (OMC, 2018a; Baena, 2018); en cuyo caso los países motivados por la incertidumbre tienden a incrementar las barreras a los flujos comerciales, lo que sucesivamente puede desencadenar en una situación más compleja asociada a guerras comerciales (Baena, Montoya y Torres, 2017).

No cabe dudas de que la firma de un Tratado de Libre Comercio (TLC) supone un camino más fácil y relativamente rápido para liberalizar el comercio con determinados socios comerciales; lo anterior, respecto 
Unión Europea y Japón: ¿El tratado de libre comercio más grande del mundo?

Baena Rojas, José Jaime y Cardona Montoya, Giovanny

a la construcción de otras iniciativas más ambiciosas y elaboradas a nivel políticoeconómico, tal y como sucede por ejemplo con una integración económica o incluso aún a través del sistema multilateral de comercio, en donde no siempre los países logran consenso en torno a ciertos temas comerciales, como sucedió precisamente en Doha con la única ronda de negociación hasta ahora de la OMC (Lindberg y Alvstam, 2012; Baldwin, 2016).

Por lo tanto, en este artículo se pretende analizar específicamente las generalidades del TLC que se ha venido negociando desde hace más de cinco años, y que recientemente fue firmado y finalmente ratificado a principios del año 2019 entre la Unión Europea (UE) y Japón; y en cuyo caso, destaca el importante efecto de esta nueva zona de libre comercio a nivel mundial. Igualmente, este trabajo analiza, en el apartado de los resultados, diversas cifras relacionadas con las características de este TLC y sucesivamente plantea, en las conclusiones, una serie de reflexiones finales.

\section{Revisión de la literatura}

\section{1. ¿Qué son los TLC y qué incidencia poseen dentro del comercio internacional?}

Según Lynch (2010), la globalización de la economía mundial se caracteriza por el notable crecimiento de los flujos comerciales en mercancías, servicios e inversión extranjera; $\mathrm{y}$ es precisamente en este sentido que los TLC constituyen una herramienta entre los países para gestionar todo este fenómeno, puesto que estos permiten incrementar el acceso a los mercados, promover la inversión, protegerse de las medidas comerciales desleales, entre muchas otras situaciones más.

En relación a los TLC es relevante agregar que estos, como acuerdos internacionales, suelen apuntar siempre a consolidar una zona de libre comercio en donde dos o incluso más países reducen o eliminan las restricciones aduaneras, tanto BA como BNA, para el comercio recíproco de productos; y en cuyo caso además todo este proceso de liberalización está precedido de un período de transición, donde de una manera paulatina y en ciertos casos asimétrica, los estados tienden progresivamente a suprimir las trabas al comercio bilateral según las capacidades y complementariedad de las economías implicadas (Cardona, 2017).

Cabe destacar que en general los acuerdos comerciales internacionales provienen de las denominadas zonas preferenciales de comercio, las cuales pueden ser entendidas como iniciativas que hacen alusión a acuerdos entre países, o bloques comerciales, y cuyo objetivo es el de promover la liberalización del comercio de bienes, capitales e incluso servicios (Navarro, 2014).

Estas zonas preferenciales de comercio, véase Gráfico I, poseen dos tipologías según su naturaleza; la primera de éstas, las uniones aduaneras - muy propias de la integración económica- que se caracterizan porque sus miembros establecen para todo el conjunto de productos $\mathrm{y} / \mathrm{o}$ universo arancelario un arancel interno común y para terceros países no miembros, un arancel más alto conocido como arancel externo común, además de que en esta figura los países miembros desarrollan profundos compromisos políticos todos estos asociados a la supranacionalidad. Y la segunda, las zonas de libre cambio -muy propias de los TLC- en cuyo caso, los países miembros no establecen un arancel externo común, puesto que cada parte podrá incluso firmar otros acuerdos con otros países, en donde se apunte al mismo propósito de liberalizar el comercio con aranceles bajos, para aquellos productos en donde sea posible según las necesidades de cada parte implicada (Kolb, 2008). 


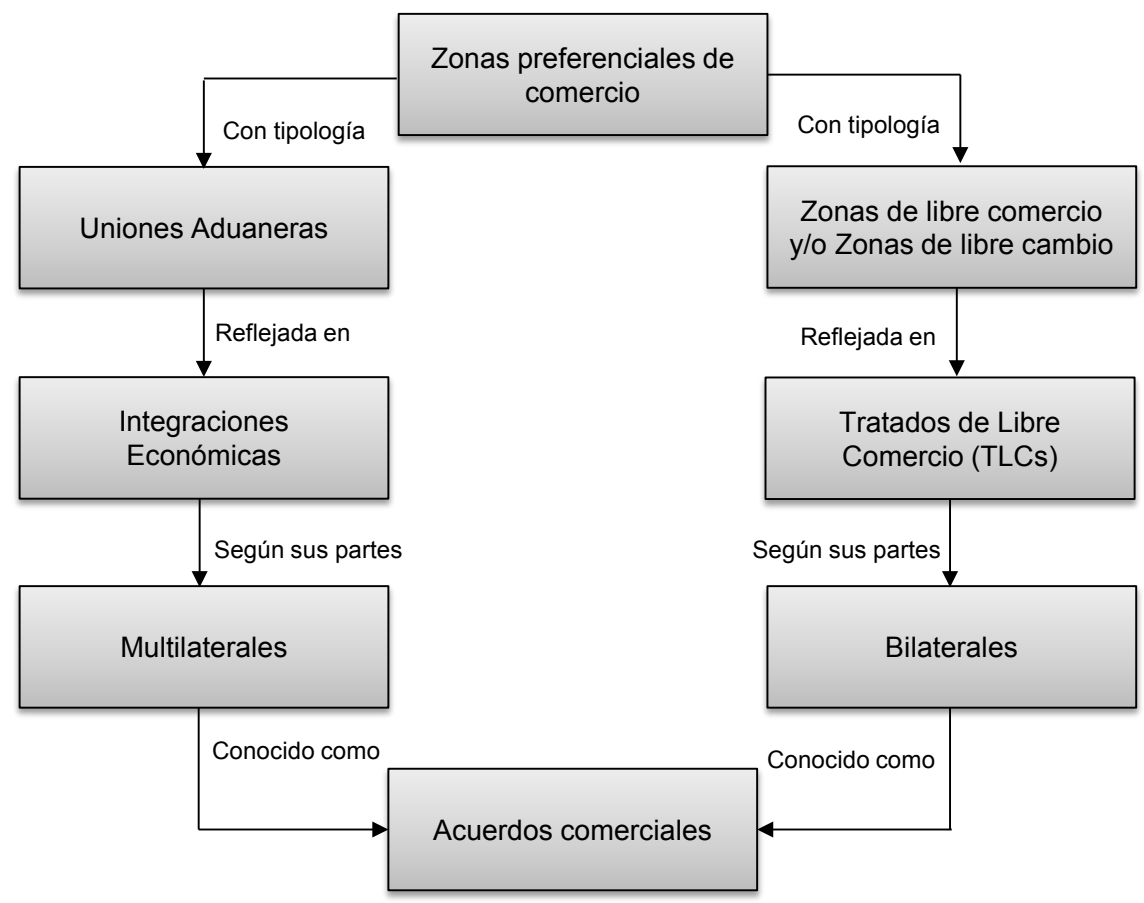

Fuente: Elaboración propia, 2019, basado en Kolb (2008) y OMC (2018b). Gráfico I. Representación de las zonas preferenciales de comercio

Respecto a estos acuerdos comerciales en general es necesario agregar también que estos se encuentran regulados tanto por el artículo XXIV: “Aplicación territorial - Tráfico fronterizo, Uniones aduaneras y zonas de libre comercio" del GATT como también por la "Cláusula de Habilitación" de la Ronda de Tokio. De este modo, ambas disposiciones normativas legitiman este tipo de acuerdos de diferente tipología (ver Tabla 1), siempre $\mathrm{y}$ cuando tales no representen un detrimento para comercio de terceros países. Aunque la interpretación de esta norma parece quedarse cada vez más corta, debido a la dinámica actual de estos tratados, en donde cada vez son acordados nuevos aspectos que previamente no se contemplaron en el GATT y que asimismo parecen socavar significativamente, por las disposiciones al margen de la OMC, el ordenamiento jurídico del sistema multilateral de comercio (Kinoshita y Barbosa, 2015). 


\section{Tabla 1}

\section{Comparativo entre TLC, como zonas de libre cambio e integraciones económicas, como uniones aduaneras}

\begin{tabular}{|c|c|c|c|}
\hline \multicolumn{2}{|c|}{$\begin{array}{c}\text { TLC } \\
\text { (Zonas de Libre Cambio) }\end{array}$} & \multicolumn{2}{|c|}{$\begin{array}{l}\text { Integraciones Económicas } \\
\text { (Uniones Aduaneras) }\end{array}$} \\
\hline Estático & $\begin{array}{l}\text { Se negocian preferencias } \\
\text { arancelarias y asuntos de orden } \\
\text { comercial que no cambian en el } \\
\text { tiempo. }\end{array}$ & Dinámico & $\begin{array}{l}\text { Se negocian no solo preferencias } \\
\text { arancelarias sino también } \\
\text { asuntos que van más allá de lo } \\
\text { comercial y que se ajustan según } \\
\text { la evolución del acuerdo en } \\
\text { diferentes etapas o niveles. }\end{array}$ \\
\hline $\begin{array}{l}\text { Comercio } \\
\text { asimétrico }\end{array}$ & $\begin{array}{l}\text { Firmados también por estados de } \\
\text { diferente condición económica } \\
\text { además de que los compromisos en } \\
\text { cuanto a liberalización comercial } \\
\text { no necesariamente serán los } \\
\text { mismos entre las partes. }\end{array}$ & Comercio simétrico & $\begin{array}{l}\text { Firmados por estados que } \\
\text { pertenecen a una región común } \\
\text { que por lo general ostenta } \\
\text { similitudes en sus condiciones } \\
\text { económicas y políticas. En estos } \\
\text { se propende por el crecimiento } \\
\text { mancomunado, debido a } \\
\text { que se los compromisos de } \\
\text { liberalización deber ser iguales. }\end{array}$ \\
\hline Temas comerciales & $\begin{array}{l}\text { En el acuerdo son negociados temas } \\
\text { concernientes al intercambio de } \\
\text { productos en general para ampliar } \\
\text { el mercado de bienes y servicios } \\
\text { entre las partes. }\end{array}$ & Temas políticos & $\begin{array}{l}\text { En el acuerdo son negociados } \\
\text { no solo temas alusivos al } \\
\text { intercambio de productos sino } \\
\text { también asuntos de orden, } \\
\text { político, social e incluso de } \\
\text { seguridad. }\end{array}$ \\
\hline $\begin{array}{l}\text { Primarización } \\
\text { productiva }\end{array}$ & $\begin{array}{l}\text { Se tiende a generar una competencia } \\
\text { productiva entre las partes, ya que } \\
\text { cualquier medida de coordinación } \\
\text { puede ser contraría al principio } \\
\text { de libre comercio de este tipo de } \\
\text { acuerdo. }\end{array}$ & $\begin{array}{l}\text { Articulación } \\
\text { productiva }\end{array}$ & $\begin{array}{l}\text { Se tienden a generar medidas } \\
\text { de coordinación y planificación } \\
\text { como componentes de asistencia } \\
\text { al desarrollo y promoción } \\
\text { productiva. Lo anterior a fin } \\
\text { de alcanzar complementación } \\
\text { productiva y acordar incluso } \\
\text { regímenes comunes de } \\
\text { protección. }\end{array}$ \\
\hline $\begin{array}{l}\text { Erosión del } \\
\text { Estado-Nación }\end{array}$ & $\begin{array}{l}\text { Se pueden generar medidas } \\
\text { vinculantes entre las partes que } \\
\text { debilitan el modelo de Estado- } \\
\text { nación además de conllevar } \\
\text { a posibles escenarios de } \\
\text { confrontación y subordinación } \\
\text { frente a la contraparte desarrollada. }\end{array}$ & Supranacionalidad & $\begin{array}{l}\text { Se busca un modelo de } \\
\text { construcción política en donde } \\
\text { los estados partes del acuerdo } \\
\text { definen un marco normativo } \\
\text { común por encima de sus } \\
\text { legislaciones nacionales. }\end{array}$ \\
\hline Subordinación & $\begin{array}{l}\text { En el modelo se presenta una } \\
\text { participación supeditada a las } \\
\text { condiciones económicas y políticas } \\
\text { de las partes implicadas. }\end{array}$ & Igualdad & $\begin{array}{l}\text { En el modelo se busca la } \\
\text { participación activa y equitativa } \\
\text { de las partes implicadas. }\end{array}$ \\
\hline $\begin{array}{l}\text { Arancel general } \\
\text { para terceros }\end{array}$ & $\begin{array}{l}\text { Cada parte aplicará los aranceles } \\
\text { que considere a países no miembros } \\
\text { del acuerdo según la cláusula de la } \\
\text { Nación Más Favorecida. }\end{array}$ & $\begin{array}{l}\text { Arancel externo } \\
\text { común para terceros }\end{array}$ & $\begin{array}{l}\text { Las partes implicadas aplicarán } \\
\text { igualitariamente un arancel para } \\
\text { países no miembros a fin de } \\
\text { proteger la figura y no socavar } \\
\text { las preferencias arancelarias } \\
\text { alcanzadas dentro del acuerdo. }\end{array}$ \\
\hline
\end{tabular}

Fuente: Elaboración propia, 2019, basado en Acosta y Falconí (2005), Park y Park (2008) y Tejedor (2017). 
Asimismo, sobre los TLC también es relevante hacer mención sobre cómo ésta herramienta tuvo sus inicios en la segunda mitad del siglo XIX, específicamente con el Tratado Cobden-Chevalier firmado entre Francia e Inglaterra, el cual fijó dos precedentes únicos en la historia del comercio internacional; debido a que con este tratado, en primera instancia, los países de Europa, tras duras décadas de proteccionismo, acabaron vinculándose en un proceso conjunto de liberalización del comercio, a través de adaptaciones a este tratado inicial. Y en segunda instancia, porque se empleó la cláusula de la Nación Más Favorecida (NMF), la cual exige que aquellos países que ratifican un acuerdo, deben otorgar mutuamente las mejores condiciones que cada uno de éstos dispense a cualquier otro país; situación que ha llegado a ser uno de los rasgos más característicos de todos los tratados comerciales posteriores (Lazer, 1999; Lobejón, 2001).

En cualquier caso, es necesario aclarar que dentro del sistema multilateral de comercio existen otras tipologías de acuerdos comerciales, los cuales suelen derivarse de las denominadas zonas preferenciales de comercio; y que incluso pueden ser entendidas como etapas previas a los TLC tal y como sucede con los acuerdos de alcance parcial o también etapas previas a las integraciones económicas como sucede con las uniones aduaneras (Pierola, 2007; OMC, 2013; Börzel y Risse, 2016).

\subsection{Algunas razones para que la Unión Europea y Japón firmen un TLC}

Según Anderson (2005), desde la perspectiva del sistema multilateral de comercio, el mundo debe propender por la disminución de todas aquellas políticas restrictivas de tipo BA y BNA que terminan interfiriendo en la circulación de los flujos comerciales; situación que de acuerdo a la evidencia empírica perjudica a la mayoría de las economías que adoptan este tipo de medidas proteccionistas, puesto que se generan situaciones de ineficiencia y distorsiones, dentro de los intercambios comerciales de los países.

Sin embargo, es evidente que si bien la OMC, como principal institución del Sistema Multilateral de Comercio, propende por promover el libre comercio sin discriminaciones, además trabajar activamente por ser garante de las negociaciones comerciales multilaterales; en ciertas oportunidades se ve significativamente afectada por la falta de voluntad entre sus países miembros (Baena y Cardona, 2019). Situación que ha venido conllevando a importantes fracasos de consenso, los cuales han generado a su vez un debate en torno a una posible crisis en la $\mathrm{OMC}$, que obligaría a importantes cambios estructurales dentro del organismo. Teniendo en cuenta además, que dentro de la OMC existen en los procesos de negociación dos principios claves; el primero de estos sostiene que las decisiones se adoptan por consenso y el segundo principio, sostiene que nada está acordado hasta que todo esté acordado (Jones, 2011; Farrands, 2018).

Todo lo anterior, es en buena medida una importante razón por la cual los TLC, parecen tomar un importante protagonismo, cuando las decisiones dentro del sistema multilateral de comercio no se hacen manifiestas del modo esperado; puesto que los mismos, permiten que los países miembros interesados logren concertar y regular una multiplicidad de temas concretos en materia comercial, que por motivos políticos estiman tardar demasiado dentro de la OMC, cuando las negociaciones de las conferencias ministeriales no logran llegar a finalizar satisfactoriamente (Alvstam, Kettunen y Ström, 2017).

Precisamente Oxley (2004), agrega que los TLC tienden cada vez más a aumentar a nivel mundial, debido a que éstos también crean oportunidades para asegurar los beneficios de liberalización que las normas del GATT y los demás textos jurídicos no prevén en determinadas circunstancias, proporcionando de este modo alternativas para negociar compromisos con otros países, que se alienten a promover también la liberalización 
Unión Europea y Japón: ¿El tratado de libre comercio más grande del mundo?

Baena Rojas, José Jaime y Cardona Montoya, Giovanny

del comercio.

Por ello según Baldwin (2006), la UE se erige como un importante paradigma de liberalización comercial y desarrollo económico a nivel mundial, en donde la promoción del libre comercio ha permitido alcanzar interesantes resultados para los países miembros de este sobresaliente grupo de países y/o bloque comercial, que en términos generales ha logrado gestionar de manera sobresaliente el fenómeno de la globalización.

No hay duda entonces de que la UE tiende a tornarse como un ejemplo fehaciente de cómo la liberalización y apertura económica pueden constituir una estrategia de política comercial para impulsar el desarrollo y la competitividad, a fin de aumentar el crecimiento económico de un grupo de países, tal y como se evidencia en la iniciativa "Global Europe"; la cual apunta a promover todo un programa de acción compuesto por una ambiciosa agenda interna y externa, conocida como la estrategia de Lisboa, en cuyo caso se refleja todo el plan de desarrollo de la UE que intenta hacer frente a todos los retos de la globalización (EUR-Lex, 2006).

En este sentido, se podría decir que además la UE ha venido precisamente enfocando su política comercial intentando hacer un mayor uso de los TLC, dadas las posibilidades que esta figura ofrece, para liberalizar el comercio con sus socios comerciales más a fines. Todo esto sin quedar rezagada a la dinámica actual del comercio internacional y sin depender de consensos entre tantas partes, tal y como sucede dentro de la OMC. Cabe destacar también, que si bien la UE no tiene un modelo de TLC para formar la base de las negociaciones con todos los socios, tal y como otros países lo han logrado, esta suele desarrollar negociaciones muy específicas para cada caso, lo cual le ha permitido lograr interesantes avances en este apartado además de alcanzar una notable cantidad de TLC (Woolcock, 2007).

Teniendo entonces en cuenta el enfoque del comercio exterior de la UE, en cuyo caso se busca la liberalización del comercio de ciertos socios comerciales a través de la firma de los
TLC, es evidente que este grupo de países está significativamente abocado a llevar a cabo nuevas alianzas con mercados asiáticos, dados sus actuales indicadores que hacen a muchas de estas economías completamente atractivas para este bloque comercial (Razeen, 2007; Prats, 2011).

De este modo, no hay duda alguna de que Japón representa un atractivo mercado puesto que su población, la cual, si bien ha venido disminuyendo en los últimos años, es actualmente superior a los 126 millones de habitantes ocupando así la décima posición a nivel mundial (Statistics Japan, 2018). Además la economía japonesa es considerada una de las economías más atractivas en el mundo por su notable crecimiento durante los últimos años, haciendo de este país uno de los Estados con mayor poder adquisitivo explicado en buena medida por su sobresaliente progreso tecnológico (Drysdale y Huang, 1997), igualmente por evidenciar una cultura que ha estado altamente avocada al consumo por su realidad social actual (Barlés y Almazán, 2010).

En contraste, al caso de la UE cabe anotar que la economía japonesa ha sido considerada históricamente como cerrada, teniendo en cuenta el enfoque de su comercio exterior, y especialmente su paradigma cultural, en cuyo caso se promovió a ultranza las exportaciones y la competitividad de su industria nacional; todo ello, haciendo de su mercado local un escenario de difícil acceso para las empresas extranjeras en buena parte de sus sectores (Pelegrín y Jensana, 2011). De hecho, es posible agregar que todo el asunto del difícil acceso al mercado japonés, tradicionalmente se convirtió en uno de los temas más complejos de las relaciones comerciales bilaterales con Estados Unidos, su principal socio comercial en occidente.

Asimismo, este acceso cerrado al mercado, ha tenido que ver también con las estrategias de política comercial y monetaria, que se implementaron en Japón para contener la crisis de 1990 que terminó por valorizar su moneda local, a un tal punto que los costos de inversión irremediablemente socavaron todo 
el interés de los norteamericanos y europeos por penetrar ese mercado, dada su incapacidad por sostener cualquier unidad de producción en el país nipón (Cervera, 1996; Solís, 2010).

Es en parte por todos estos motivos que la economía japonesa ha llegado a ser considerada como una economía neomercantilista, predatoria y proteccionista, que durante muchos años fue un importante actor de guerras comerciales; una situación que se explicaba por el mantenimiento de complejas redes de clientes preferentes, que llegaron a desarrollar un cuestionado sistema de distribución, casi impenetrable, en donde intervenían numerosos intermediarios (Holcombe, 2016).

No obstante, el enfoque de la política de comercio exterior de Japón, ha venido experimentando importantes cambios desde la primera década del siglo XXI, que han permitido dejar atrás la férrea posición del gobierno, que durante mucho tiempo restringió la presencia de empresas extranjeras; lo que ha permitido romper con todo el imaginario de que el idioma, las costumbres laborales, las BA así como las BNA, y especialmente el complejo sistema de distribución, entre otras tantas dificultades más, particularmente de orden cultural, no pueden ser superadas al momento de negociar con el país nipón (Czinkota y Kotabe, 2000).

Es así entonces como la economía japonesa, al igual que otras economías avanzadas, ha venido participando de procesos de liberalización y apertura económica, como estrategia de política comercial para impulsar su propio desarrollo, en este caso a través del Japan External Trade Office (JETRO), entendido como una serie de iniciativas para promover la inversión extranjera y la apertura comercial, en un intento por hacer frente a la posición tradicionalista del país, como también, a las tendencias del entorno generadas por la globalización; lo que en definitiva ha conllevado a importantes cambios de liberalización comercial, la cual ha llegado incluso a destacar en relación a otras economías desarrolladas (Abegglen, 2006; Pelegrín y Jensana, 2011).
Es por este motivo que Ravenhill (2010), señala que la proliferación de los TLC dentro de los países de Asia oriental, tiene que ver no solo con las enseñanzas de la crisis económica, que experimentaron diversos países en esa región a finales de los noventas; sino también, con el hecho de que actualmente la firma de acuerdos comerciales suele ser vista como una política comercial, la cual puede garantizar a los exportadores nacionales japoneses, y a otros países de esta zona, competir en igualdad de condiciones, respecto a los exportadores rivales de otros países, que se benefician de acuerdos comerciales preferenciales firmados por sus gobiernos.

Precisamente Capling (2008), afirma que la proliferación de acuerdos comerciales preferenciales en la región de Asia-Pacífico, se considera en general como una respuesta pragmática de los gobiernos al estancamiento de las instituciones comerciales regionales y multilaterales encabezadas por la $\mathrm{OMC}$, además de que la firma de este tipo de tratados, tienden a denotar implicaciones geopolíticas y estratégicas dentro de la política exterior de los mismos países.

En este orden de ideas, no hay duda que tanto para la UE como para Japón, podría resultar conveniente firmar un TLC, debido a los retos que supone el asombroso crecimiento económico, e incluso de gobernanza, que la República Popular China ha venido alcanzando a nivel mundial; todo esto además de balancear la creciente interdependencia comercial, que puede suponer todo este enorme mercado tanto para Japón como para la UE.

De este modo, para la misma UE puede igualmente representar una oportunidad de diversificar sus relaciones comerciales con otras economías protagonistas dentro del continente asiático, dado que es en esta región donde se encuentran algunos de sus principales socios comerciales en la actualidad, por lo tanto, para lograrlo es imprescindible entonces desplegar toda la diplomacia europea, la cual muy seguramente permitirá desbloquear el comercio de esta región. Una situación, que sin dudas facilitaría a toda la EU avanzar rápidamente en la construcción 
Unión Europea y Japón: ¿El tratado de libre comercio más grande del mundo?

Baena Rojas, José Jaime y Cardona Montoya, Giovanny

de un paradigma comercial, que dinamice su acceso al mercado en Asia; puesto que este último continente en un futuro albergará muy posiblemente las economías más grandes del mundo (Inkster, 2001; Bungenberg y Hazarika, 2017).

De hecho todo lo anterior, parece tener cada vez más sentido, especialmente cuando otras potencias económicas como Estados Unidos, tienden a interesarse por implementar, pese a las lecciones que se debieron aprender del pasado, nuevas políticas para incrementar significativamente las BA y BNA en contra del gigante asiático, todo ello en un intento por acelerar y dinamizar su economía; no obstante, toda esta situación ha originado una guerra comercial con China, que sucesivamente podría conllevar a efectos perjudiciales para el bienestar social, no solo de ambos países sino también para el de socios comerciales, que se verían colateralmente afectados por un escenario de proteccionismo de estas proporciones (Guo, Lu, Sheng y Yu, 2018).

En definitiva, la creación de un TLC entre la UE y Japón puede suponer por lo tanto no solo un escenario de liberalización del comercio, sino que incluso éste puede redundar positivamente en el mejoramiento en general de las relaciones entre ambas partes, precedidas por un complejo panorama de neomercantilismo, entre la década de 1970 y buena parte de la década de 1980, el cual parece haberse dejado atrás. Y si bien tradicionalmente han existido importantes retos en materia de relaciones exteriores a nivel bilateral, marcadas por un notable tradicionalismo y un sólido protocolo que evidencia contrastes en la cosmovisión de ambas partes, tanto la UE y Japón han venido trabajando arduamente para desarrollar medidas más claras en materia política y económica; en cuyo caso se han logrado promover el dialogo, la cooperación y la apertura pasando de este modo de la retórica a la acción (Keck, Vanoverbeke y Waldenberger, 2013).

Es precisamente en este sentido, que a finales de la primera mitad del año 2018 se ha anunciado al mundo la firma de este nuevo acuerdo comercial, cuya ratificación se logró en los primeros meses del año 2019, el cual parece generar interesantes expectativas dado que este agrupa dos de las cuatro mayores economías del mundo, asimismo, propone una liberalización histórica en ciertos sectores clave entre sus partes; además porque este TLC se genera en uno de los momentos de mayor incertidumbre, en donde el proteccionismo comercial por parte de Estados Unidos parece atentar contra el sistema multilateral de comercio (Guo, Lu, Sheng y Yu, 2018; Morgade, 2018; Baena y Cardona, 2019).

\section{Metodología}

En la primera parte del presente artículo sobre la revisión de la literatura fueron consultadas bases de datos de revistas de alto impacto científico como Web of Science (WOS) de Clarivate Analytics, Scopus de Elsevier, entre otras bases de datos por medio de las cuales fueron rastreados trabajos académicos, que sucesivamente permitieron ahondar y reflexionar en el marco teórico antes descrito.

Es relevante señalar además, que a nivel metodológico la propuesta intenta llevar a cabo un análisis descriptivo que permita la caracterización de los TLC a nivel mundial, destacando particularmente el TLC UE y Japón; todo lo anterior analizando datos secundarios publicados por instituciones internacionales de alto reconocimiento y confiabilidad, principalmente a través de la Organización Mundial de Comercio (OMC), y su base de datos Regional Trade Agreements Information System (RTA-IS).

Igualmente son tenidas en cuenta otras importantes bases de datos publicadas en páginas web de la United Nations Conference on Trade and Development (UNCTAD), Global Trade Alert (GTA), la Organización para la Cooperación y el Desarrollo Económico (OCDE), entre otras páginas más, las cuales permitieron el acceso a información general sobre los TLC que actualmente existen, con lo cual fue posible la construcción de los resultados, en cuyo caso fueron llevadas a cabo 
gráficas propias de estadística descriptiva, las cuales permitieron en definitiva la consecución de la presente investigación. En este orden de ideas toda esta propuesta pretende evidenciar la trascendencia del TLC UE y Japón, teniendo en cuenta no solo su peso en materia de comercio internacional, sino también algunos aspectos de comercio exterior de las dos partes implicadas.

\section{Resultados y discusión}

Antes que nada y a fin de ser más precisos en el análisis de los resultados es importante destacar que dentro del sistema multilateral de comercio, tal cual como el Gráfico I indicó, existe una multiplicidad de acuerdos comerciales en cuyo caso destacan principalmente los TLC. Por lo tanto, a nivel general se puede decir que actualmente existen alrededor de 305 acuerdos comerciales en vigor, en cuyo caso sus Estados miembros liberalizan el tráfico comercial de bienes y servicios.

En este sentido, con la ratificación definitiva del TLC UE y Japón se han alcanzado para el año 2019 un total de 306 acuerdos comerciales ${ }^{(1)}$, tal como se muestra en el Gráfico II, de los cuales 153 de estos, equivalentes a $50 \%$ son acuerdos comerciales exclusivamente de mercancías. Unos 152, que representan el $49,67 \%$ son acuerdos comerciales en donde se contemplan preferencias arancelarias para el tráfico no solo de mercancías sino incluso para servicios; mientras que apenas un acuerdo, equivalente al $0,33 \%$ tendrá que ver con la regulación de flujos comerciales únicamente para servicios, como es el caso concreto del acuerdo "Espacio Económico Europeo", propio de la UE como integración económica.

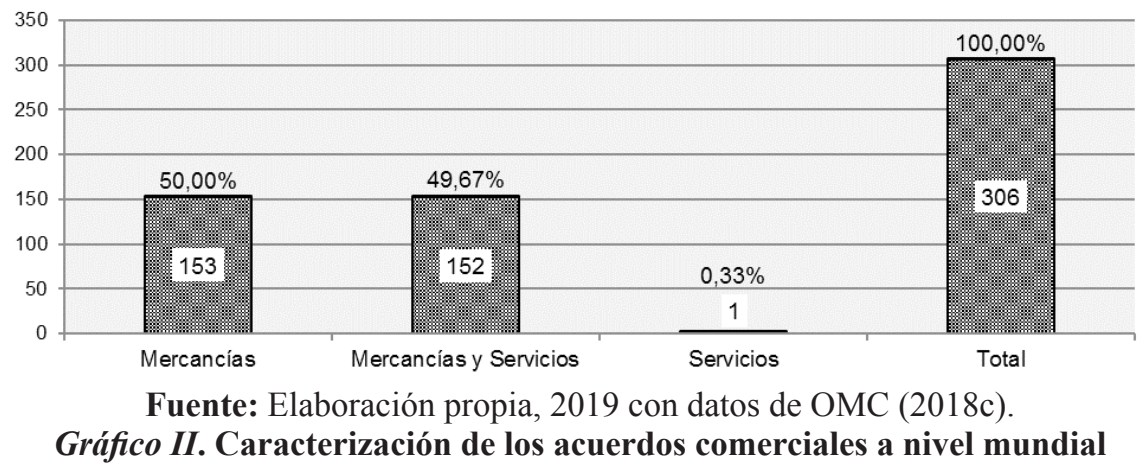

De otro lado, la caracterización de los acuerdos comerciales dentro de la OMC parte igualmente de la idea anterior del Gráfico I, en cuyo caso son representadas las zonas de libre comercio y/o zonas preferenciales de comercio. Por ello, si bien es cierto que los TLC no son iguales a las integraciones económicas, la OMC devela casos en donde se efectúan categorizaciones en ciertos acuerdos comerciales, que parecen cumplir con las dos tipologías, dado que en principio las zonas de libre cambio pueden avanzar en situaciones puntuales a una unión aduanera e incluso avanzar en casos mucho más complejos a una integración económica.

Por lo tanto, para la OMC de los 306 acuerdos comerciales en vigor, incluyendo el presente nuevo TLC UE y Japón, se puede observar en el Gráfico III, que unos 140 de estos equivalentes al $45,75 \%$ serán 
Unión Europea y Japón: ¿El tratado de libre comercio más grande del mundo?

Baena Rojas, José Jaime y Cardona Montoya, Giovanny

interpretados simultáneamente como tratados de libre comercio y acuerdos de integración económica. Mientras que 112 de estos correspondientes a un $36,60 \%$ serán entendidos exclusivamente como acuerdos de libre comercio, en tanto que 24 de ellos,

que representan el 7,84\% serán concebidos exclusivamente como acuerdos de alcance parcial y 18 de estos acuerdos, equivalentes a $5,88 \%$ serán percibidos exclusivamente como uniones aduaneras.

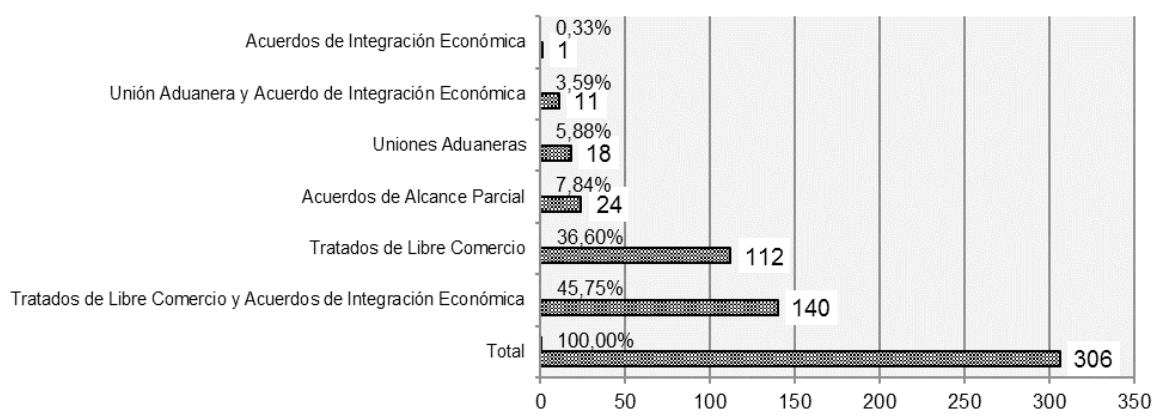

Fuente: Elaboración propia, 2019 con datos de OMC (2018c). Gráfico III. Tipos de acuerdos comerciales a nivel mundial

Asimismo, se puede apreciar que 11 de estos equivalentes a un 3,59\% serán entendidos simultáneamente como unión aduanera y acuerdo de integración económica, mientras que tan solo un acuerdo de todos estos, es decir el 0,33\% será interpretado como una integración económica. En otras palabras la OMC tipifica la naturaleza singular de los acuerdos comerciales en una o dos categorías, según su objeto y fin o el modo en que estos tienden a ser implementados, teniendo en cuenta que los tratados entre países se pueden llevar a cabo entre Estados como también entre bloques comerciales conformados por Estados.

De esta manera y considerando el caso puntual del acuerdo comercial entre la UE y Japón es posible resaltar que el presente TLC aplica tanto para mercancías como para servicios, aunque concretamente este trabajo está enfocado para el primer caso, por lo cual se puede decir que el mundo ha alcanzado mucho más de 112 TLC en vigor para el año 2019. De igual modo, este nuevo acuerdo comercial entre la UE y Japón, como zona de libre comercio, ha alcanzado hasta la fecha los valores más altos tanto en exportaciones, importaciones y PIB a nivel mundial, convirtiéndolo en la zona de libre comercio más grande del mundo.

Por lo tanto, de acuerdo a la Tabla 2 es posible identificar que de las exportaciones mundiales, las cuales ascienden a unos 17.735 millones de dólares, el TLC UE y Japón, ocupa el primer lugar con más de 6.584 millones de dólares equivalentes a un $37,13 \%$ mientras que el TLC, en donde participa nuevamente una de las partes, UE y Corea del Sur, se ubica en el segundo lugar con más de 6.460 millones de dólares en exportaciones, representando un $36,43 \%$ y así sucesivamente en otros TLC más, en donde se mantiene la participación de la UE; la cual a nivel particular es también la unión aduanera e integración económica más exitosa a nivel mundial. 
Tabla 2

Los TLC más grandes a partir de algunos indicadores de comercio exterior

\begin{tabular}{|c|c|c|c|c|c|c|c|}
\hline $\mathbf{N}^{\circ}$ & TLC & Exportaciones & $\%$ & Importaciones & $\%$ & PIB total* & $\%$ \\
\hline 1 & UE y Japón & 6.584 .715 .633 & $37,13 \%$ & 6.452 .684 .500 & $36,11 \%$ & 22.149 .834 & $27,45 \%$ \\
\hline 2 & UE y Corea del Sur & 6.460 .245 .813 & $36,43 \%$ & 6.259 .679 .361 & $35,03 \%$ & 18.808 .448 & $23,31 \%$ \\
\hline 3 & UE y Canadá & 6.307 .120 .235 & $35,57 \%$ & 6.213 .931 .220 & $34,77 \%$ & 18.930 .740 & $23,46 \%$ \\
\hline 4 & $\begin{array}{l}\text { UE y México } \\
\text { UE y Comunidad de }\end{array}$ & 6.296 .069 .822 & $35,51 \%$ & 6.201 .579 .307 & $34,70 \%$ & 18.427 .616 & $22,84 \%$ \\
\hline 5 & $\begin{array}{l}\text { Desarrollo de África } \\
\text { Austral }\end{array}$ & 6.056 .211 .973 & $34,15 \%$ & 5.945 .129 .138 & $33,27 \%$ & 17.938 .454 & $22,23 \%$ \\
\hline 6 & $\begin{array}{l}\text { UE Colombia, Perú y } \\
\text { Ecuador }\end{array}$ & 5.986 .931 .679 & $33,76 \%$ & 5.886 .834 .554 & $32,94 \%$ & 17.901 .334 & $22,19 \%$ \\
\hline 7 & UE y Chile & 5.955 .847 .702 & $33,59 \%$ & 5.846 .271 .925 & $32,71 \%$ & 17.554 .773 & $21,76 \%$ \\
\hline 8 & UE y Egipto & 5.912 .561 .691 & $33,34 \%$ & 5.847 .549 .088 & $32,72 \%$ & 17.513 .066 & $21,71 \%$ \\
\hline 9 & UE y Ghana & 5.899 .522 .278 & $33,27 \%$ & 5.793 .798 .690 & $32,42 \%$ & 17.325 .027 & $21,47 \%$ \\
\hline $\begin{array}{l}10 \\
11 \\
12\end{array}$ & $\begin{array}{l}\text { ASEAN y China } \\
\text { China y Corea del Sur } \\
\text { China y Australia }\end{array}$ & $\begin{array}{l}3.565 .583 .794 \\
2.836 .961 .949 \\
2.493 .497 .788\end{array}$ & $\begin{array}{l}20,11 \% \\
16,00 \% \\
14,06 \%\end{array}$ & $\begin{array}{l}3.086 .960 .316 \\
2.320 .353 .166 \\
2.070 .325 .735\end{array}$ & $\begin{array}{l}17,27 \% \\
12,98 \% \\
11,59 \%\end{array}$ & $\begin{array}{l}14.713 .270 \\
13.768 .451 \\
13.561 .121\end{array}$ & $\begin{array}{l}18,24 \% \\
17,06 \% \\
16,81 \%\end{array}$ \\
\hline 13 & $\begin{array}{l}\text { Tratado de Libre Comercio } \\
\text { de América del Norte** }\end{array}$ & 2.376 .022 .247 & $13,40 \%$ & 3.261 .485 .284 & $18,25 \%$ & 22.193 .566 & $27,51 \%$ \\
\hline 14 & China y Chile & 2.332.563.838 & $13,15 \%$ & 1.906 .945 .730 & $10,67 \%$ & 12.514 .776 & $15,51 \%$ \\
\hline 15 & China y Nueva Zelanda & 2.301.384.867 & $12,98 \%$ & 1.882 .012 .438 & $10,53 \%$ & 12.443 .553 & $15,42 \%$ \\
\hline 16 & China y Georgia & 2.266 .062 .544 & $12,78 \%$ & 1.849 .866 .381 & $10,35 \%$ & 12.252 .859 & $15,19 \%$ \\
\hline 17 & $\begin{array}{l}\text { Estados Unidos y Corea } \\
\text { del Sur }\end{array}$ & 2.119 .696 .447 & $11,95 \%$ & 2.886 .864 .311 & $16,15 \%$ & 20.921 .355 & $25,93 \%$ \\
\hline 18 & Estados Unidos y Singapur & 1.910 .241 .057 & $10,77 \%$ & 2.726 .094 .084 & $15,25 \%$ & 19.714.511 & $24,43 \%$ \\
\hline 19 & ASEAN y Corea del Sur & 1.875 .876 .582 & $10,58 \%$ & 1.723 .545 .485 & $9,64 \%$ & 4.006 .321 & $4,97 \%$ \\
\hline 20 & Estados Unidos y Australia & 1.776 .232 .286 & $10,02 \%$ & 2.636 .836 .881 & $14,76 \%$ & 20.714 .025 & $25,67 \%$ \\
\hline 21 & Estados Unidos y Chile & 1.615.298.336 & $9,11 \%$ & 2.473 .456 .875 & $13,84 \%$ & 19.667 .680 & $24,38 \%$ \\
\hline 22 & ASEAN e India & 1.600 .625 .443 & $9,03 \%$ & 1.692 .317 .297 & $9,47 \%$ & 5.073 .061 & $6,29 \%$ \\
\hline 23 & Estados Unidos y Perú & 1.590 .307 .028 & $8,97 \%$ & 2.448 .159 .058 & $13,70 \%$ & 19.601 .993 & $24,29 \%$ \\
\hline 24 & Estados Unidos y & 1.583 .021 .909 & $8,93 \%$ & 2.454 .410 .657 & $13,73 \%$ & 19.699 .795 & $24,42 \%$ \\
\hline 25 & Estados Unidos y & 1.571 .423 .178 & $8,86 \%$ & 2.453 .344 .372 & $13,73 \%$ & 19.499 .743 & $24,17 \%$ \\
\hline 26 & $\begin{array}{l}\text { ASEAN, Australia y Nueva } \\
\text { Zelanda }\end{array}$ & 1.570 .462 .707 & $8,86 \%$ & 1.513 .646 .494 & $8,47 \%$ & 4.004 .844 & $4,96 \%$ \\
\hline 27 & Estados Unidos y Panamá & 1.557 .519 .079 & $8,78 \%$ & 2.428 .695 .144 & $13,59 \%$ & 19.452 .442 & $24,11 \%$ \\
\hline 28 & Japón y México & 1.107 .548 .567 & $6,25 \%$ & 1.091 .843 .419 & $6,11 \%$ & 6.022 .056 & $7,46 \%$ \\
\hline 29 & Japón y Singapur & 1.062 .269 .168 & $5,99 \%$ & 989.173 .246 & $5,54 \%$ & 5.196 .044 & $6,44 \%$ \\
\hline 30 & Japón y Suiza & 997.405 .882 & $5,62 \%$ & 938.975 .802 & $5,25 \%$ & 5.551 .024 & $6,88 \%$ \\
\hline 31 & Japón e India & 996.473 .419 & $5,62 \%$ & 1.118 .715 .286 & $6,26 \%$ & 7.469 .628 & $9,26 \%$ \\
\hline 32 & Canadá y Corea del Sur & 994.129 .160 & $5,61 \%$ & 911.190 .194 & $5,10 \%$ & 3.183 .794 & $3,95 \%$ \\
\hline $\begin{array}{l}33 \\
34 \\
35 \\
36\end{array}$ & $\begin{array}{l}\text { EFTA y Corea del Sur } \\
\text { Corea del Sur y Singapur } \\
\text { Japón y Tailandia } \\
\text { Japón y Australia }\end{array}$ & $\begin{array}{l}979.762 .428 \\
937.799 .348 \\
932.819 .802 \\
928.260 .396\end{array}$ & $\begin{array}{l}5,53 \% \\
5,29 \% \\
5,26 \% \\
5,23 \%\end{array}$ & $\begin{array}{l}838.441 .272 \\
796.168 .108 \\
895.976 .999 \\
899.916 .043\end{array}$ & $\begin{array}{l}4,69 \% \\
4,46 \% \\
5,01 \% \\
5,04 \%\end{array}$ & $\begin{array}{l}2.638 .668 \\
1.854 .658 \\
5.327 .358 \\
6.195 .558\end{array}$ & $\begin{array}{l}3,27 \% \\
2,30 \% \\
6,60 \% \\
7,68 \%\end{array}$ \\
\hline $\begin{array}{l}37 \\
38 \\
39 \\
40 \\
41\end{array}$ & $\begin{array}{l}\text { Japón y Malasia } \\
\text { India y Corea del Sur } \\
\text { EFTA y México } \\
\text { Corea del Sur y Australia } \\
\text { Corea del Sur y Vietnam }\end{array}$ & $\begin{array}{l}914.525 .618 \\
872.003 .599 \\
815.586 .437 \\
803.790 .576 \\
787.950 .198\end{array}$ & $\begin{array}{l}5,16 \% \\
4,92 \% \\
4,60 \% \\
4,53 \% \\
4,44 \%\end{array}$ & $\begin{array}{l}730.170 .726 \\
925.710 .148 \\
780.341 .218 \\
706.910 .905 \\
690.198 .787\end{array}$ & $\begin{array}{l}4,09 \% \\
5,18 \% \\
4,37 \% \\
3,96 \% \\
3,86 \%\end{array}$ & $\begin{array}{l}5.186 .637 \\
4.128 .242 \\
2.257 .836 \\
2.854 .172 \\
1.754 .615\end{array}$ & $\begin{array}{l}6,43 \% \\
5,12 \% \\
2,80 \% \\
3,54 \% \\
2,17 \%\end{array}$ \\
\hline 42 & EFTA y Singapur & 770.307 .038 & $4,34 \%$ & 677.671 .045 & $3,79 \%$ & 1.431 .824 & $1,77 \%$ \\
\hline $\begin{array}{l}43 \\
44 \\
45\end{array}$ & $\begin{array}{l}\text { Japón y Chile } \\
\text { Japón y Perú } \\
\text { India y Singapur }\end{array}$ & $\begin{array}{l}767.326 .446 \\
742.335 .138 \\
662.548 .209\end{array}$ & $\begin{array}{l}4,33 \% \\
4,19 \% \\
3,74 \%\end{array}$ & $\begin{array}{l}736.536 .037 \\
711.238 .220 \\
764.939 .920\end{array}$ & $\begin{array}{l}4,12 \% \\
3,98 \% \\
4,28 \%\end{array}$ & $\begin{array}{l}5.149 .213 \\
5.083 .526 \\
2.921 .398\end{array}$ & $\begin{array}{l}6,38 \% \\
6,30 \% \\
3,62 \%\end{array}$ \\
\hline 46 & Corea del Sur y Chile & 642.856 .626 & $3,63 \%$ & 543.530 .899 & $3,04 \%$ & 1.807 .827 & $2,24 \%$ \\
\hline 47 & $\begin{array}{l}\text { Corea del Sur y Nueva } \\
\text { Zelanda }\end{array}$ & 611.677 .655 & $3,45 \%$ & 518.597 .607 & $2,90 \%$ & 1.736 .604 & $2,15 \%$ \\
\hline 48 & Corea del Sur y Colombia & 610.580 .199 & $3,44 \%$ & 524.484 .681 & $2,93 \%$ & 1.839 .942 & $2,28 \%$ \\
\hline 49 & India y Malasia & 514.804 .659 & $2,90 \%$ & 641.096 .921 & $3,59 \%$ & 2.911 .991 & $3,61 \%$ \\
\hline 50 & Canadá y Chile & 489.731 .048 & $2,76 \%$ & 497.782 .758 & $2,79 \%$ & 1.930 .119 & $2,39 \%$ \\
\hline 51 & México y Chile & 478.680 .636 & $2,70 \%$ & 485.430 .844 & $2,72 \%$ & 1.426 .995 & $1,77 \%$ \\
\hline 52 & EFTA y Chile & 475.364 .317 & $2,68 \%$ & 425.033 .836 & $2,38 \%$ & 1.384 .993 & $1,72 \%$ \\
\hline 53 & Canadá y Ucrania & 463.930 .182 & $2,62 \%$ & 482.160 .182 & $2,70 \%$ & 1.765 .197 & $2,19 \%$ \\
\hline 54 & Canadá y Colombia & 457.454 .621 & $2,58 \%$ & 478.736 .540 & $2,68 \%$ & 1.962 .234 & $2,43 \%$ \\
\hline
\end{tabular}


Unión Europea y Japón: ¿El tratado de libre comercio más grande del mundo?

Baena Rojas, JoséJaime y Cardona Montoya, Giovanny

Cont... Tabla 2

\begin{tabular}{rlcccccc}
\hline 55 & EFTA y Colombia & 443.087 .889 & $2,50 \%$ & 405.987 .618 & $2,27 \%$ & 1.417 .108 & $1,76 \%$ \\
56 & EFTA y Panamá y Costa & 428.127 .018 & $2,41 \%$ & 395.796 .788 & $2,21 \%$ & 1.226 .812 & $1,52 \%$ \\
57 & Rica & 413.604 .298 & $2,33 \%$ & 380.379 .434 & $2,13 \%$ & 1.147 .985 & $1,42 \%$ \\
58 & EFTA y Jordania & 408.863 .023 & $2,31 \%$ & 367.954 .488 & $2,06 \%$ & 1.123 .076 & $1,39 \%$ \\
59 & Turquía y Malasia & 373.483 .218 & $2,11 \%$ & 427.647 .603 & $2,39 \%$ & 1.165 .602 & $1,44 \%$ \\
60 & Asociación Surasiática & 369.674 .300 & $2,08 \%$ & 599.942 .513 & $3,36 \%$ & 3.291 .738 & $4,08 \%$ \\
& para la Cooperación & 349.943 .247 & $1,97 \%$ & 314.081 .218 & $1,76 \%$ & 3.014 .357 & $3,74 \%$ \\
61 & Mercosur y Egipto & 303.951 .870 & $1,71 \%$ & 289.564 .424 & $1,62 \%$ & 732.297 & $0,91 \%$ \\
62 & Tailandia y Chile & 299.392 .465 & $1,69 \%$ & 293.503 .468 & $1,64 \%$ & 1.600 .497 & $1,98 \%$ \\
63 & Australia y Chile & 106.182 .088 & $0,60 \%$ & 111.077 .245 & $0,62 \%$ & 586.267 & $0,73 \%$ \\
64 & Colombia y Chile & r. &
\end{tabular}

*Este valor está expresado en billones por lo cual deben ser agregados seis ceros más de acuerdo a la escala numérica larga hispanoparlante.

** El presente TLC es completamente sui generis considerando que se rompe su naturaleza de bilateral dado que actualmente está constituido por tres partes como son Canadá, Estados Unidos y México en donde las concesiones arancelarias varían según las negociaciones entre las mismas partes.

Fuente: Elaboración propia, 2019 con datos de UNCTAD (2018) y Banco Mundial (2018).

En el caso de las importaciones mundiales, las cuales ascienden a unos 17.870 millones de dólares, este nuevo acuerdo comercial también alcanza el primer lugar como TLC con más de 6.452 millones de dólares equivalentes a un $36,11 \%$ seguido nuevamente del TLC UE y Corea del Sur, con más de 6.259 millones de dólares representando el 35,03\% entre otros tantos TLC más.

Para el análisis del PIB total mundial, el cual asciende a unos 80,6 billones de dólares, tanto el Tratado de Libre Comercio de América del Norte que alcanza los 22,19 billones de millones de dólares equivalentes a un $27,51 \%$ como el TLC UE y Japón con unos 2,19 billones de dólares correspondientes al $27,45 \%$, comparten el primer lugar en este indicador, además seguido de otros tantos acuerdos comerciales de este tipo.

De otro lado, si se analizara el comportamiento del comercio exterior del TLC UE y Japón a nivel individual, tal como se puede apreciar en el Gráfico IV, ambas partes destacan significativamente por su notable participación, especialmente en el caso de la UE que alcanza un tercio del total de las exportaciones mundiales.

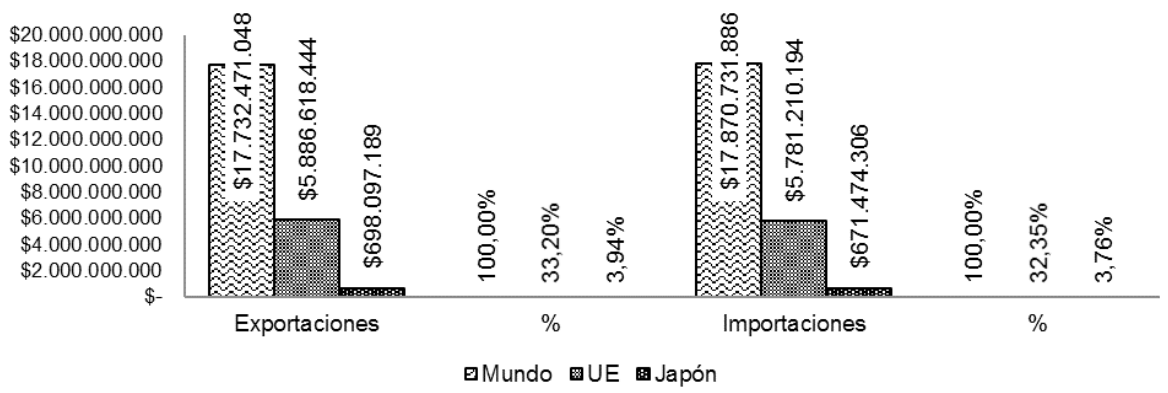

Fuente: Elaboración propia, 2019 con datos de UNCTAD (2018) y OEC (2018). Gráfico IV. Exportaciones e importaciones de EU y Japón en el mundo 
Así pues resulta evidente que la UE con más de 5.886 millones de dólares equivalentes a $33,20 \%$ supera ocho veces las exportaciones de Japón, que exceden los 698 millones de dólares consonantes al 3,94\% de las exportaciones totales mundiales. Situación bastante similar en el caso de las importaciones en donde la UE con 5.781 millones de dólares que representan el 32,35\% también supera ocho veces las importaciones de Japón con más de 671 millones de dólares equivalentes a $3,76 \%$ de las importaciones mundiales.

Subsecuentemente si se analizara el comercio exterior de las partes del presente
TLC entre sí, como se muestra en el Gráfico V, el panorama sería llamativo, puesto que si bien en términos absolutos la UE exporta más hacía Japón que lo que éste último país hacia la UE, el porcentaje de Japón dobla el porcentaje de la UE, es decir que Japón es más dependiente de ese mercado respecto a la dependencia de la UE sobre Japón. Por lo cual, la UE termina exportando más de 306 millones de dólares equivalentes a $5.20 \%$ hacia el mercado de Japón. Mientras que Japón apenas exporta 90 millones de dólares equivalentes a $13,00 \%$ hacia el mercado de la UE.

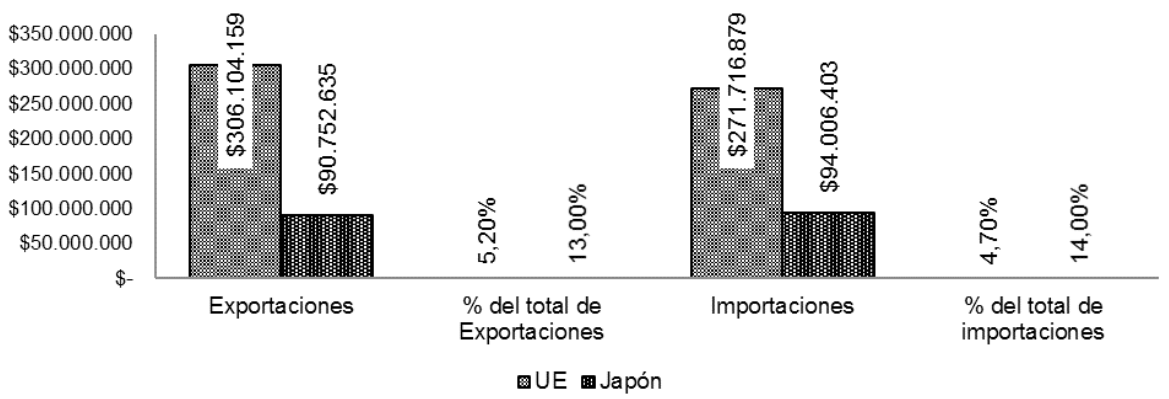

Fuente: Elaboración propia, 2019 con datos de EUROSTAT (2018). Gráfico $V$. Exportaciones e importaciones de EU y Japón dentro del TLC

En contraste, a nivel de importaciones la Unión Europea adquiere desde Japón un valor que supera los 271 millones de dólares equivalente a 4,70\% mientras que Japón importa desde la UE poco más de 94 millones de dólares lo cual representa el 14\%.
Por último, a nivel de proteccionismo de tipo BA, es relevante señalar como se puede observar en el Gráfico VI, que la UE ostenta actualmente aranceles promedio NMF significativamente más altos que en el caso de Japón. 
Unión Europea y Japón: ¿El tratado de libre comercio más grande del mundo?

Baena Rojas, José Jaime y Cardona Montoya, Giovanny

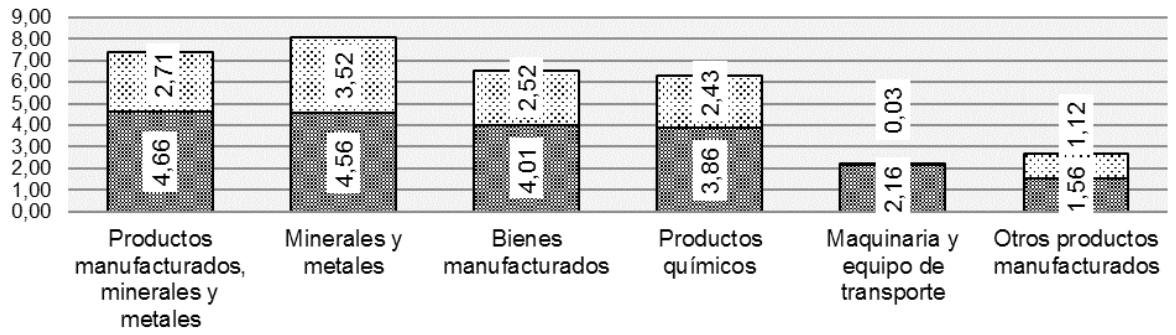

붕 ๑Japan

Fuente: Elaboración propia, 2019 con datos de UNCTAD (2018).

\section{Gráfico VI. Nivel de proteccionismo arancelario promedio asociado a BA entre la} UE y Japón

En este sentido, al analizar a nivel general los diferentes sectores productivos de ambos países, se puede detectar que los productos manufacturados minerales y metales, para el caso de la UE se aplican aranceles promedio de $4,66 \%$, mientras que Japón presenta aranceles de apenas 2,71\%; en cuanto a minerales y metales la UE maneja una media de $4,56 \%$ y Japón de 3,52\%, en bienes manufacturados la UE 4,01\% mientras que Japón $2,52 \%$, en el caso de productos químicos la UE $3,86 \%$ en tanto que Japón $2,43 \%$, en lo concerniente a maquinaria y equipo de transporte la UE
$2,16 \%$ y Japón $0,03 \%$ y finalmente, en lo que corresponde a otros productos manufacturados la UE 1,56\% y Japón 1,12\%.

Con respecto al proteccionismo adoptado de tipo BNA, en el Gráfico VII, también se evidencia una superioridad en este apartado de la UE respecto a Japón. Es claro entonces que la UE ha venido acumulando hasta la fecha un total de 4.306 medidas de proteccionismo general asociado a BNA equivalentes a un $44,40 \%$; mientras que Japón acumula apenas unas 228 medidas correspondientes a un $2,35 \%$.

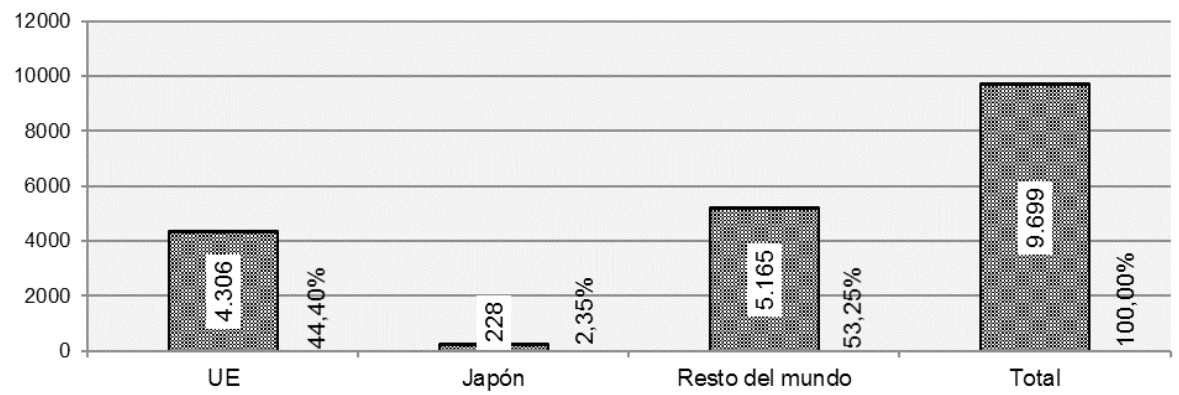

Fuente: Elaboración propia, 2019 con datos de GTA (2018).

Gráfico VII. Nivel de proteccionismo promedio asociado a BNA entre la UE y Japón 


\section{Conclusiones}

Es relevante señalar que algunos acuerdos comerciales pueden ser categorizados en diferentes tipologías a la vez, dado su objeto y fin o el modo en que estos tienden a ir desarrollándose en el tiempo; aspectos que pueden evidenciar entonces características en común, tal y como sucede con la caracterización que efectúa actualmente la Organización Mundial de Comercio.

En este caso la firma del TLC entre la Unión Europea y Japón supone entonces la configuración de la zona de libre cambio más grande del mundo, no solo en términos de comercio exterior, a partir de algunos indicadores como la cantidad de exportaciones e importaciones, sino también a nivel económico, por el volumen mismo de PIB; esto en relación a los demás acuerdos de esta misma naturaleza. Así pues, cabe agregar que se evidencia una primacía a nivel económico de aquellos acuerdos comerciales constituidos por partes, que a su vez están integradas por diversos países, formando una organización internacional, lo cual supone claramente un incremento en los indicadores de las partes implicadas en relación a acuerdos comerciales configurados entre países directamente.

En relación al presente TLC es importante agregar que entre ambas partes el mayor volumen de comercio, tanto por concepto de exportaciones como de importaciones a nivel mundial, lo alcanza la EU respecto a Japón. Situación que lógicamente se ve reflejada en el comercio bilateral, puesto que la UE si bien en términos porcentuales apenas vende el 5,20\% del total de sus exportaciones hacia Japón frente a un $13 \%$ de este último país hacia la UE además de comprar apenas un 4,70\% del total de sus importaciones desde Japón frente a un 14\% de este último país desde la UE. En términos absolutos el escenario es distinto; debido a que la UE exporta tres veces más hacia Japón lo que este último hacia la UE, además de importar casi tres veces más desde Japón lo que este último desde la UE.

También cabe agregar que si bien para ambas partes este TLC representa, a nivel general, interesantes oportunidades de acceso a mercados, el caso de la EU en términos de liberalización comercial parece ser más significativo en relación a Japón, puesto que precisamente este último país evidencia niveles de proteccionismo comercial más bajos a nivel de BA y BNA, respecto a la UE.

Finalmente, el TLC entre la UE y Japón constituye, a propósito de la coyuntura actual, una interesante oportunidad para demostrar como dos economías altamente desarrolladas, pueden llevar a cabo iniciativas de liberalización comercial pese a las recientes fricciones de esta índole, entre economías de occidente y oriente como sucede con Estados Unidos y China respectivamente.

\section{Notas}

1 Es importante destacar que en la presente cifra se han tenido en cuenta solo los acuerdos actualmente en vigor incluyendo las respectivas adhesiones de nuevos miembros en algunos de éstos tratados comerciales. De igual modo, es preciso también agregar que en esta cifra tampoco han sido tenidos en cuenta los 34 arreglos comerciales preferenciales (ACPs) registrados en la base de datos de la OMC, debido a que si bien éstos son también tratados comerciales como tal; su naturaleza en cuyo caso son otorgadas concesiones arancelarias unilaterales de países desarrollados a países en vía de desarrollo para la cooperación internacional, hace de los ACPs tratados no recíprocos para la liberalización del comercio tal cual como se pretende analizar en el presente estudio. En este sentido, de no ser tenidas en cuenta las 15 adhesiones, por tratarse al fin y al cabo del mismo tratado, y de incluirse los 34 ACPs el total de acuerdos comerciales vigentes dentro de la OMC sería de alrededor de 325. 
Unión Europea y Japón: ¿El tratado de libre comercio más grande del mundo?

Baena Rojas, José Jaime y Cardona Montoya, Giovanny

\section{Referencias bibliográficas}

Abegglen, J. (2006). 21st-Century Japanese Management: New systems, lasting values. New York: Palgrave Macmillan.

Acosta, A., y Falconí, F. (2005). TLC más que un tratado de libre comercio. Quito: Editorial Flacso.

Alvstam, C., Kettunen, E., y Ström, P. (2017). The service sector in the free-trade agreement between the EU and Singapore: Closing the gap between policy and business realities. Asia Europe Journal, 15(1), 75-105.

Anderson, K. (2005). On the virtues of multilateral trade negotiations. Economic Record, 81(225), 414-438.

Baena, J., Montoya, A., y Torres, D. (2017). La crisis económica mundial ¿La proliferación del proteccionismo como una causa efecto? En-Contexto, 5(6), 185-207.

Baena, J. (2018). Barreras arancelarias y no arancelarias como restricciones al comercio internacional. Revista Venezolana de Gerencia, 23(83), 543-562.

Baena, J., y Cardona, G. (2019). Elemental considerations about the largest FTA in the world between the EU and Japan. 33 a Conferencia International Business Information Management Association (IBIMA), Granada, España.

Baldwin, M. (2006). EU trade politics - Heaven or hell? Journal of European Public Policy, 13(6), 926-942.

Baldwin, R. (2016). The world trade organization and the future of multilateralism. Journal of Economic Perspectives, 30(1), 95-116.

Banco Mundial (2018). Gross domestic product 2017. Recuperado de http://da- tabank.worldbank.org/data/download/ GDP.pdf

Barlés, E., y Almazán, V. (2010). Japón y el mundo actual. Zaragoza, España: Prensas Universitarias de Zaragoza.

Basaldúa, R. X. (2014). La Organización Mundial de Comercio: objetivos, principios y medios. La ronda de Doha. En G. Pardo (Coord..), Acuerdos comerciales y aspectos relacionados con el comercio exterior (pp. 119-148). Bogotá, Colombia: Editorial Universidad del Rosario.

Börzel, T., y Risse, T. (2016). The oxford handbook of comparative regionalism. Londres: Oxford University Press.

Bungenberg, M., y Hazarika, A. (2017). The European Union's trade and investment policy in Asia: New challenges and opportunities in a changing global environment - or: following individual roadmaps. Asia Europe Journal, 15(4), 377-397.

Capling, A. (2008). Preferential trade agreements as instruments of foreign policy: An Australia-Japan free trade agreement and its implications for the Asia Pacific region. Pacific Review, 21(1), 27-43.

Cardona, G. (2017). Comercio mundial tendencias y estructura. Medellín, Colombia: Editorial CEIPA.

Cardona, G. (2018). Integración económica y cooperación internacional: Entre el multilateralismo, el regionalismo y la supranacionalidad. Medellín, Colombia: Editorial La Sallista.

Cervera, M. (1996). Globalización japonesa: Lecciones para América Latina. Ciudad de México: Siglo XXI Editores.

Czinkota, M., y Kotabe, M. (2000). Entering the Japanese market a reassessment of foreign firms' entry and distribution strategies. Industrial Marketing Ma- 
nagement, 29(6), 483-491.

Drysdale, P., y Huang, Y. (1997). Technological catch-up and economic growth in East Asia and the Pacific. Economic Record, 73(222), 201-211.

EUR-Lex (2006). Una Europa global: Competir en el mundo. Recuperado de https:// eur-lex.europa.eu/legal-content/ES/ TXT/?uri=LEGISSUM $\% 3 \operatorname{Ar} 11022$

EUROSTAT (2018). International trade in goods. Recuperado de http://ec.europa.eu/eurostat/statistics-explained/ index.php?title=International trade in goods

Farrands, C. (2018). A comment on global governance, multilateralism and the management of international trade. En D. Sagarika, Global Governance: Perspectives, Challenges and Outlook (pp. 173-191). Nottingham: Nova Science Publishers, Inc.

Fernández, X. (2009). Globalización económica, soberanía de los estados y políticas sociales: Funciones y retos del derecho internacional ante el "Trilema" de la globalización. Sociedad Global. Revista de Relaciones Internacionales y Ciencias Políticas, 3(1), 43-84.

Global Trade Alert - GTA (2018). Global Dynamics. Recuperado de https://www. globaltradealert.org/global dynamics/area all/year-from 2017/yearto 2017

Guo, M., Lu, L., Sheng, L., y Yu, M. (2018). The day after tomorrow: Evaluating the Burden of Trump's trade war. Asian Economic Papers, 17(1), 101120.

Holcombe, C. (2016). Una historia de Asia oriental: De los orígenes de la civilización al siglo XXI. Ciudad de México: Fondo de Cultura Económica.

Inkster, I. (2001). Japanese industrialisation: Historical and cultural perspectives.
London: Routledge Taylor and Francis Group.

Jones, K. (2011). The doha blues: Institutional crisis and reform in the WTO. Oxford: Oxford University Press.

Keck, J., Vanoverbeke, D., y Waldenberger, F. (2013). EU-Japan relations, 19702012: From confrontation to global partnership. New York: Routledge.

Kinoshita, F., y Barbosa, P. (2015). Análisis de las normas aplicables a los acuerdos comerciales regionales en materia de mercancías. Revista Jurídica da Presidência, 17(113), 471-494.

Kolb, R. (2008). Encyclopedia of business ethics and society. London: SAGE publications.

Krueger, A. (1997). Free trade agreements versus customs unions. Journal of Development Economics, 54(1), 169-187.

Lacarte, J., y Granados, J. (2004). Solución de controversias comerciales e inter-gubernamentales: Enfoques multilaterales y regionales. Buenos Aires, Argentina: Editorial Instituto para la integración de América Latina y el Caribe.

Lazer, D. (1999). The free trade epidemic of the 1860s and other outbreaks of economic discrimination. World Politics, 51(4), 447-483.

Lindberg, L., y Alvstam, C. (2012). The ambiguous role of the WTO in times of stalled multilateral negotiations and proliferating FTAs in east Asia. International Negotiation, 17(1), 163-187.

Lobejón, L. (2001). El comercio internacional. Madrid, España: Ediciones Akal.

Lynch, D. (2010). Trade and globalization: An introduction to regional trade agreements. New York: Rowman \& Littlefield Publishers Inc.

Morgade, A. (18 de julio de 2018). Acuerdo 
Unión Europea y Japón: ¿El tratado de libre comercio más grande del mundo?

Baena Rojas, José Jaime y Cardona Montoya, Giovanny

comercial entre la Unión Europea y Japón: 3 claves para entender por qué este pacto es tan importante (y el mensaje que envía a Donald Trump). British Broadcasting Corporation BBC News. Recuperado de https://www. bbc.com/mundo/noticias-internacional-44862348

Muñoz, M. D. P., Cabrita, M. D. R., Ribeiro, M. L., y Diéguez, G. (2015). Técnicas de gestión empresarial en la globalización. Revista de Ciencias Sociales, XXI(3), 346-357.

Navarro, L. (2014). El integracionismo o el sur buscando al sur. Justicia, 1(25), 162170.

Observatory of Economic Complecity - OEC (2018). Japón. Recuperado de https:// atlas.media.mit.edu/en/profile/country/jpn/

Organización Mundial de Comercio - OMC (2013). Acuerdos Comerciales Regionales $(A C R)$ y la OMC. Recuperado de https://ecampus.wto.org/admin/files/ Course 469/CourseContents/RTAR1-S-Print.pdf

Organización Mundial de Comercio - OMC (2018a). Un informe de vigilancia muestra que han aumentado las nuevas restricciones comerciales de los miembros de la OMC. Recuperado de https://www.wto.org/spanish/news s/ news 18 s/trdev 25 jul18 s.htm

Organización Mundial de Comercio - OMC (2018b). Acuerdos Comerciales Regionales y Arreglos Comerciales Preferenciales. Recuperado de https:// www.wto.org/spanish/tratop s/region $\mathrm{s} / \mathrm{rta}$ pta $\mathrm{s} . \mathrm{htm}$

Organización Mundial de Comercio - OMC (2018c). Sistema de información sobre los Acuerdos Comerciales Regionales (SI-ACR). Recuperado de http://rtais. wto.org/UI/PublicMaintainRTAHome. $\underline{\operatorname{aspx}}$
Oxley, A. (2004). The rise of free trade agreements. Telecommunications Journal of Australia, 54(4), 5-10.

Park, I., y Park, S. (2008). Free Trade Agreements versus Customs Unions: An examination of east Asia. Korea University, 1(1301), 1-34.

Pelegrín, A., y Jensana, A. (2011). Economía de Japón. Barcelona, España: Editorial OUC.

Pierola, F. (2007). Solución de diferencias ante la OMC: Presente y perspectivas. Londres: Cameron May.

Prats, E. (2011). Possibilities of a FTA between EU and Japan. Is the EU - South Korea FTA a right model for a future FTA with Japan? (Tesis de Maestría). Uppsala University. Recuperado de https://www.researchgate.net/publication/306286837 Outline of the master thesis Possibilities of a FTA between EU and Japan Is the EU - South Korea FTA a right model_for_a future FTA with_Japan

Ravenhill, J. (2010). The 'new East Asian regionalism': A political domino effect. Review of International Political Economy, 17(2), 178-208.

Razeen, S. (2007). Looking East: The European Union's new FTA negotiations in Asia. Recuperado de https://www.econstor. eu/bitstream/10419/174856/1/ecipe-jtpe-2007-03.pdf

Solís, R. (2010). La crisis financiera del Japón de los años 90: Algunas lecciones de la década perdida, 1992-2003. Análisis Económico, XXV(60), 201-239.

Statistics Japan (2018). Statistics Boreau Monthly Report. Recuperado de http:// www.stat.go.jp/english/data/jinsui/ tsuki/index.html

Tejedor, J. (2017). Theories and methods of regional integration and free trade agreement. Revista de Economía Mundial, 
1(47), 223-242.

United Nations Conference on Trade and Development - UNCTAD (2018). UNCTAD Stat. Recuperado de http://unctadstat.unctad.org/wds/ReportFolders/ reportFolders.aspx?sCS ChosenLan- $\mathrm{g}=\mathrm{en}$

Woolcock, S. (2007). European Union policy towards Free Trade. European Centre For International Political Economy, 1(3), 1-15. 